\section{$\Psi$ \\ Revista \\ de Psicologia}

ISSN 2179-1740

\title{
A IDENTIDADE DO "ANTIPETISMO" E DO "PETISMIO" EM NARRATIVAS DE SIMPATIZANTES DO PARTIDO DOS TRABALHADORES
}

\author{
THE IDENTITY OF "ANTIPETISMO" AND "PETISMO" IN NARRATIVES OF THE PARTIDO \\ DOS TRABALHADORES
}

\author{
Pedro de Oliveira Filho ${ }^{1}$ \\ Willey Pereira dos Santos ${ }^{2}$ \\ Heloisa Maria da Silva Castro ${ }^{3}$
}

\section{Resumo}

As investigações da Operação Lava Jato e a mobilização de grupos de direita contra o Partido dos Trabalhadores (PT) o colocaram no momento mais crítico de sua história. Neste contexto, o objetivo deste estudo é identificar e analisar, nessa situação de conflito aberto com seus adversários políticos, a construção de atributos identitários para petistas e antipetistas em relatos de simpatizantes do Partido dos Trabalhadores. Para isso foram analisados, com o uso do método da análise de discurso proposto pela psicologia social discursiva, comentários produzidos em reposta às postagens do site Conversa Afiada do jornalista Paulo Henrique Amorim, alinhado politicamente com o Partido dos Trabalhadores no ano de 2015. Trata-se de um site muito frequentado por simpatizantes do Partido dos Trabalhadores. Na análise foram identificadas as categorias que os simpatizantes e militantes do "petismo" mobilizam quando falam de si mesmos e dos adversários políticos. Observou-se que a desonestidade, o conservadorismo e o antinacionalismo são traços centrais na identidade do "antipetismo" construída pelos petistas. 0 pertencimento à esquerda política, por outro lado, apresenta-se como um traço central da identidade do movimento em que se inserem esses militantes, movimento esse que estaria sendo vítima, segundo eles, de um golpe organizado por uma direita constituída pelo empresariado, a grande mídia e setores do Estado brasileiro.

Palavras-chave: Antipetismo; petismo; discurso; identidade

\section{Abstract}

The investigations of Operação Lava Jato and the mobilization of right-wing groups against the Partido dos Trabalhadores (PT) put it at the most critical moment in its history. In this context, the objective of this study is to identify and analyze, in this situation of open conflict with its political opponents, the construction of identity attributes for petistas and antipetistas in reports of sympathizers of the Partido dos Trabalhadores. For this were analyzed using the discourse analysis method proposed by discursive social psychology, comments made in response to posts site Conversa Afiada journalist Paulo Henrique Amorim, politically aligned with the Partido dos Trabalhadores in 2015. It's a site majority frequented by sympathizers of the Partido dos Trabalhadores. The analysis categories were identified that supporters and "petismo" militants mobilize when they speak of themselves and of political opponents. It was observed that dishonesty, conservatism and anti-nationalism are central features in the identity of "antipetismo" built by PT. Belonging to the political left, on the other hand, presents itself as a central feature of the movement's identity in which they operate these militants, a movement which would be the victim, they said, a coup organized by a right constituted by the business community, the media and sectors of the brazilian state.

Keywords: Antipetismo; petismo; discourse; identity.

\footnotetext{
1 Doutor em Psicologia Social e Professor Associado da Universidade Federal de Campina Grande, Brasil. Email: deoliveirafilhopedro@gmail.com. https://orcid.org/0000-0003-2401-8953

2 Graduado em Psicologia pela Universidade Federal de Campina Grande, Brasil. Email: will.lecter@gmail.com https://orcid.org/0000-0002-5055-6782

3 Graduada em Psicologia pela Universidade Federal de Campina Grande, Brasil. Email:heloisa_castro@hotmail.com https://orcid.org/0000-0001-5414-1739
} 


\section{INTRODUÇÃO}

Este estudo investiga a construção da identidade de petistas e antipetistas em textos de militantes e simpatizantes do Partido dos Trabalhadores (PT) na internet, procurando identificar as ações realizadas e os recursos retóricos mobilizados nesse processo de construção identitária.

De acordo com Du Preez (1980), a identidade deve ser um tema central na política pois é a identidade dos grupos que torna a ação política possível, na medida em que, sem uma identidade comum, grupos de indivíduos não se tornam agentes coletivos.

Mas a identidade não é um dado pré-discursivo que simplesmente se reflete na ação e nas práticas representacionais que grupos formulam para definir a si mesmos e aos outros grupos. Como afirmam Laclau e Mouffe (1985), as identidades de indivíduos e grupos são estabelecidas provisoriamente e precariamente como resultado de disputas e conflitos entre diferentes discursos.

Define-se identidade, neste estudo, seguindo Benwell e Stokoe (2006), como um processo essencialmente discursivo e público. Entende-se a produção discursiva de identidades como um processo indissociavelmente ligado à categorização discursiva, tal como entendida pelos psicólogos sociais discursivos (Antaki, \& Widdicombe, 2008; Billig, 1987; Edwards, 2008; Potter,1998; Potter, \& Wetherell, 1987; Wetherell, \& Potter, 1992).

Assim, quando as pessoas mobilizam categorias em suas intervenções discursivas (categorias como "negros", "brancos", "brasileiros", "argentinos", "petistas", "tucanos", etc. ) estão constituindo identidades. A depender do universo cultural e social em que as categorias são usadas para classificar pessoas elas podem ser associadas a diferentes atributos ( "honestidade", "beleza", "inteligência", "incompetência", "maldade", etc.). Tais atributos, como ressaltam vários estudos (Billig, 1987; Van Dijk, 1987; Wetherell, \& Potter, 1992), são usados para realizar diferentes ações, dentre elas desqualificar, acusar e combater aqueles que são considerados uma ameaça. Que ações os simpatizantes e militantes do Partido dos Trabalhadores realizam quando descrevem os seus adversários e a si mesmos ao longo desse conflito que se tornou mais agressivo a partir de 2013?

O PT passa pelo momento mais difícil de sua existência. Poucos negariam que o impacto da Operação Lava Jato na imagem do partido foi devastador. O partido fundado em 1980 no colégio Sion em São Paulo por intelectuais e trabalhadores passou, ao longo dos últimos treze anos, por mudanças consideráveis. Em 2003, ao chegar à presidência com Luiz Inácio Lula da Silva, o PT foi se afastando aos poucos da ideologia socialista que orientou a sua formação e se tornou muito semelhante ao PTB de antes de 1964, uma espécie de "partido dos pobres" (Singer, 2010).

Os programas sociais dos dois mandatos de Lula e do primeiro mandato de Dilma Rousseff deram ao PT um amplo apoio nas classes populares de baixa renda e nas regiões mais pobres do país (Norte e Nordeste), regiões mais beneficiadas por programas como o Programa Bolsa Família. Por outro lado, esse conjunto de políticas sociais direcionadas aos mais pobres aumentou ainda mais a hostilidade dos setores conservadores da sociedade brasileira em relação ao partido. Segundo Brugnago e Chaia (2015, p.113-115), esses setores representam o PT como a raiz de todos os males do Brasil; esse partido e todos os que o apoiam seriam "cúmplices e usurpadores da nação brasileira". Estaria maquinando "o clássico golpe comunista mascarado de democracia", golpe que roubaria "as liberdades individuais, a liberdade do prazer de consumo". Conteria em si todas "as figuras da alterideologia": "militantes marxistas, minorias como homossexuais, índios, negros, quilombolas e os pobres nordestinos dependentes da Bolsa 
Família".

O ano de 2013 marca o início da ofensiva de grupos de direita contra o PT. Os protestos iniciados pelo Movimento Passe Livre, um movimento social de esquerda, foram hegemonizados por grupos de direita, e esses grupos tornaram-se um grande movimento contra o governo do PT, que governava o pais há dez anos (Brugnago \& Chaia, 2015; Abreu \& Allegretti, 2016); e desempenharam um papel central no processo de impedimento da presidente Dilma Rousseff em 2016 (Abreu, \& Allegretti, 2016; Delcort, 2016).

Em 2018, esses grupos uniram-se, não obstante suas diferenças, contra o Partido dos Trabalhadores e deram a vitória ao candidato de ultradireita, Jair Bolsonaro, no segundo turno da eleição presidencial (Santos, 2018).

Analisar as ações realizadas discursivamente pelos simpatizantes do PT quando descrevem os adversarios/inimigos e quando descrevem o seu próprio grupo político é um tipo de investigação que se insere numa perspectiva teórica mais ampla, que compreende as produções discursivas como elementos fundamentais da constituição da vida social.

Tal perspectiva está presente nos estudos empíricos da psicologia social discursiva (Antaki, \& Widdicombe, 2008; Billig, 1987; Edwards, 2008; Potter,1998; Potter, \& Wetherell, 1987; Wetherell, \& Potter, 1992), que investiga relatos discursivos com o uso do método de análise de discurso, por meio de análises empiricamente rigorosas, atenta aos detalhes retóricos, e que privilegiam a construção social da realidade em interações cotidianas e em textos sociais de diferentes tipos. Está presente na obra de um autor como Foucault (1972) que nos ajudou a compreender o papel de discursos que atravessam amplos períodos históricos na constituição de diferentes objetos e sujeitos que passam a fazer parte de nossa realidade social. Está presente também na obra dos teóricos do discurso Laclau e Mouffe (1985), que destaca a batalha de diferentes discursos para definir a natureza da realidade social.

Essa luta de discursos para definir a natureza da realidade social tem um lugar central na análise aqui realizada. Construindo a identidade social do "petismo" e dos antagonistas do "petismo", os simpatizantes do PT recusam obstinadamente, com 0 uso de diferentes estratégias retóricas, conteúdos identitários para esse partido, conteúdos que trabalham para viabilizar a sua derrocada no cenário político brasileiro.

\section{METODO}

Trata-se de uma pesquisa exploratória, de tipo qualitativo, que utilizou o método de análise de discurso, desenvolvido pelos teóricos da Psicologia Social Discursiva (Antaki, \& Widdicombe, 2008; Billig, 1987; Edwards, 2008; Gill, 2002; Potter, 1998; Potter, \& Wetherell, 1987; Wetherel, \& Potter, 1992).

Um processo de análise de discurso discurso guiado por essa perspectiva teórico-metodológica concede uma especial atenção à função do discurso, ou seja, às ações realizadas com o uso de formulações discursivas (acusação, defesa, constituição de identidades, demonização de identidades, etc.), e às estratégias retóricas utilizadas para realizar tais ações. Olhar para as estratégias retóricas, implica em conceder uma especial atenção ao modo como 0 discurso é organizado para tornar determinadas versões da realidade factuais, verdadeiras, como se usa a categorizado e a particularização, figuras retóricas, narrativas e descrições para produzir determinados efeitos discursivos (Wetherell, \& Potter, 1992).

Foram analisados os comentários produzidos em resposta às postagens e matérias do site político Conversa 
Afiada, comandado pelo jornalista Paulo Henrique Amorim, jornalista alinhado politicamente com o Partido dos Trabalhadores no período em que os dados foram coletados, alinhamento que perdurou até a morte do jornalista em 10 de julho de 2019. Trata-se de um site frequentado majoritariamente por simpatizantes do PT e da esquerda política em geral. Duas razoes determinaram sua escolha. No período da coleta, era um dos sites de política mais populares da internet com milhares de seguidores seduzidos pelo estilo, que variava ente 0 irônico e o debochado, de Paulo Henrique Amorim. Além disso, era frequentado por simpatizantes de diferentes correntes ideológicas da esquerda e do próprio PT, e essa diversidade é importante em pesquisas qualitativas como a relatada neste estudo.

Foram selecionados todos os textos produzidos entre 28 de setembro e quatro de outubro de 2015, que comentavam postagens de Paulo Henrique Amorim e cujos temas fossem o Partido dos Trabalhadores, a esquerda em geral, a direita antipetista e a direita em geral, totalizando 510 comentários. Os comentários foram coletados no site nos dias em que foram publicados, e quando os pesquisadores entenderam que já tinham material com diversidade suficiente para uma pesquisa qualitativa encerraram a coleta. $O$ período da coleta e todo o ano de 2015 foi especialmente agonístico, marcado por uma profunda agudização da crise política que resultou no Impeachment da presidente Dilma Rousseff em 2016.

Os comentários apresentados e analisados aqui continuam com alguns erros de digitação e transgressões gramaticais que estavam presentes neles quando foram coletados no site. Somente algumas poucas alterações foram realizadas nesses comentários para torná-los mais adequados aos padrões da revista, sem alterações no conteúdo.

\section{Codificação e Análise}

A codificação, no método de análise de discurso que guia este estudo, é uma análise preliminar que tem por objetivo organizar 0 material em categorias, a partir das questões de pesquisa, para então iniciar a análise propriamente dita (Gill, 2002; Wetherell, \& Potter, 1992). Como neste estudo a questão de pesquisa é a construção discursiva da identidade do "petismo" e do "antipetismo", as passagens nos comentários supracitados que nomeavam e definiam os petistas e os antipetistas foram identificadas e categorizadas.

A análise propriamente dita, neste método, concede uma atenção especial à função do discurso, às ações que ele realiza ( Gill, 2002; Potter, \& Wetherell, 1987). Assim, construídas as categorias, procurou-se identificar as ações realizadas discursivamente e os recursos discursivos utilizados nesse processo.

\section{RESULTADOS E DISCUSSÃO}

\section{Representando os antipetistas}

Nos relatos dos petistas, os antipetistas são multifacetados, mas todas as suas faces constituem um retrato extremamente negativo dos inimigos do "petismo". Em alguns comentários eles são apresentados como mentirosos e manipuladores que usam o poder da mídia para alcançar seus objetivos anti emancipatórios, contrários aos interesses do povo e dos mais pobres. Em outros comentários se opera uma clivagem no interior da categoria antipetistas e uma parte das pessoas que fazem parte dessa categoria passa a ser definida como "massa de manobra", alienados que 
servem aos interesses de grupos poderosos que seriam de fato os beneficiários do processo de criminalização do Partido dos Trabalhadores. Os antipetistas são também representados como hipócritas, mentirosos, incompetentes, manipuladores da opinião pública (com a ajuda da grande mídia), mas também como delirantes que parecem acreditar naquilo que dizem

Pode-se afirmar que, se se toma o grupo de militantes como um todo como unidade de análise, há uma contradição na identidade do "antipetismo" construída por esses militantes e simpatizantes do "petismo". Em alguns comentários o "antipetismo" é definido como poderoso e quase invencivel por ser constituído e apoiado pelas forças mais poderosas da burguesia e do Estado brasileiro. Nesses comentários geralmente se adota um tom de desdém por aquelas narrativas que sugerem uma vitória final do "petismo". Em outros comentários, no entanto, o "antipetismo" é representado como uma força decadente e impotente que será derrotada pelo PT com o apoio do povo. Essa variabilidade discursiva é um dos fenômenos mais destacados pelos psicólogos sociais discursivos (Billig, 1987; Potter, \& Wetherell, 1987; Wetherel, \& Potter, 1992). Para esses autores, a variabilidade discursiva (inconsistências, contradições, etc.), tanto nas subjetividades individuais quanto nas subjetividades dos grupos e movimentos políticos (como essa no interior da militância petista), resulta, principalmente, dos conflitos entre diferentes discursos no interior da sociedade mais ampla. Esses conflitos se atualizam na vida subjetiva de indivíduos e grupos, por isso as inconsistências, as contradições.

Como se pode observar, são vários os atributos da direita antipetista mobilizados nesses comentários. Este estudo, no entanto, focalizará três atributos usados pelos militantes do "petismo" para construir a identidade da direita antipetista: a corrupção, o conservadorismo antidemocrático e o entreguismo (ou antinacionalismo).

$O$ tema da corrupção ao longo de todo o século XX foi usado por setores da direita contra movimentos de esquerda no Brasil. A União Democrática Nacional (UDN), comandada por seu líder Carlos Lacerda, usou essa arma contra os governos trabalhistas de Getúlio Vargas e João Goulart com notável eficácia (Skidmore, 1989; Skidmore, 2010). No contexto do conflito político atual brasileiro, o tema da corrupção tem um papel central no combate ao petismo por parte dos seus opositores (Oliveira Filho, Feitosa, \& Silva, 2019; Santos, 2014). A cobertura na grande mídia dos dois escândalos de corrupção que marcaram os governos petistas é representada pelos petistas cujos comentários foram aqui analisados como manipulação criminosa que visa transformar a palavra "petismo" em sinônimo de corrupção.

Verdade. Porém, infelizmente , o PT nas próximas eleições, pelo jeitão, para nosso grande azar e total humilhação, como nunca, antes, talvez, ocorrido na história do partido(PT) poderá ser varrido do mapa eleitoral brasileiro, não elegendo, se bobear, nem mesmo, candidato em cidade do interior do Nordeste isso graças ao trabalho intenso que o PIG e aliados fizeram de destruição em massa do PT durante esses anos todos. 0 grande beneficiado creio poderá ser o PSDB que é ultra blindado pelo PIG e por nossa justiça como sempre, que poderão ficar com as principais prefeituras governo e presidência do Brasil ou ao menos do estado de SP. Será uma espécie de ditadura do PSDB? E o PSDB no poder entregará de mão beijada (levando o seu , $\$ \$$ como sempre claro) aos americanos...Espero estar $101 \%$ errado com meus pensamentos... (Comentário do dia 28/09/2015).

Os supostos fatos que embasaram a denúncia do então Procurador Geral da República, que deu origem à AP 470, também é uma coletânea de fraudes e ilações sem nenhum fundamento e, nem por isso, deixou de servir ao espetáculo midiático que se prolongou por sete anos, de 2005 a 2012 e culminou com 
condenações em massa, sem provas, com grande pirotecnia nos meios de comunicação que foram capazes de transformar a patranha em verdade verdadeira. Com a parceria de agentes públicos do judiciário e privados donos das concessões públicas dos meios de comunicação, havendo, como há, corrupção dos dois lados, a bandidagem do Estadão pode inventar e falar o que quiser. Porque tudo virou uma esculhambação institucional generalizada e absolutamente fora de controle (Comentário do dia 02/10/2015).

Tudo isso se explica no retorno das privatarias tucanas. privatizaram até as eleições no Brasil, com o fim do financiamento privado a casa grande caiu, não tem mais como os poderosos comprarem os seus eleitos contra interesses do povo e do país (Comentário do dia 30/09/2015).

Acusar os antipetistas de corruptos (e de hipócritas porque esconderiam com o apoio da mídia sua própria corrupção enquanto amplificariam a do "petismo") certamente é um ato discursivo que faz sentido dentro desse contexto em que a acusação de corrupção dirigida ao "petismo" é compreendida como opressiva. Todas as vezes que realizam essa acusação eles procuram sair da posição identitária em que são colocados, ao mesmo tempo em que colocam lá os antipetistas. No que diz respeito ao posicionamento identitário, várias possibilidades já foram identificadas exaustivamente entre os estudiosos de análise de discurso que concedem uma atenção especial à categorização entendida como um processo discursivo intimamente associado ao processo de produção de identidades (Antaki, \& Widdicombe, 2008; Billig, 1987; Edwards, 2008; Potter,1998; Potter, \& Wetherell, 1987; Wetherell, \& Potter, 1992). Nos comentários acima, os simpatizantes recusam o conteúdo que o adversário quer colar à identidade de seu grupo. Em termos discursivos, fazem isso procurando retirar o seu partido da categoria "corrupto", seja apresentando os adversários como os verdadeiros corruptos, seja argumentando que a corrupção, enquanto prática, está presente, de alguma forma, em todos os partidos.

O primeiro comentário sugere uma aliança entre o "PIG" (Partido da Imprensa Golpista)1 e seus aliados antipetistas (com o PSDB em posição de destaque) com o objetivo de realizar a "destruição em massa do PT". Nesse como em vários outros comentários, o PSDB é representado como "o grande beneficiado" dessa aliança contra 0 "petismo", pois seria partido "ultra blindado pelo PIG e por nossa justiça" Como resultado de todo esse processo de destruição do PT, teríamos no Brasil uma "ditadura do PSDB" que poderia, "levando o seu"..."como sempre claro", entregar sem oposição as riquezas nacionais aos americanos. O PSDB, representado repetidamente por esses militantes como o grande inimigo do "petismo" no universo partidário, seria então antinacional e corrupto.

Em outro comentário, esse do dia 02/10/2015, novamente o PSDB, a justiça e a mídia emergem como entidades associadas numa aliança para destruir o PT. $O$ autor volta um pouco no tempo e sugere que essa aliança já existia em 2005 quando se iniciou a ação penal 470 (processo judicial contra políticos do PT e outros partidos aliados ao PT, popularmente conhecido como "mensalão"). Nesse julgamento o judiciário sofreu severas críticas de militantes do PT por supostamente estar atuando de forma parcial (Biroli, \& Mantovani, 2014). Não é por acaso que ao começar seu relato o comentador traça um percurso histórico que parte justamente da AP 470 para justificar a tese da contínua atitude corrupta e parcial da mídia e do judiciário contra o PT. Expressões como "corrupção", "bandidagem", "esculhambação institucional generalizada", "absolutamente fora de controle" apresentam o PT como vítima de uma aliança criminosa e corrupta capaz de tudo para destruí-lo.

No terceiro comentário, o PSDB reaparece (o tucano, como se sabe, é o símbolo do PSDB), só que agora aliado de um ator político que não é mencionado explicitamente nos comentários anteriores. Trata-se da própria elite 
burguesa nacional, os "poderosos. E essa elite é apresentada explicitamente como inimiga do povo brasileiro: ela compraria "os seus eleitos contra interesses do povo e do pais".

O termo "casa grande", muito usado entre os blogueiros petistas para nomear os antipetistas, é usado pelo sociólogo Gilberto Freyre (Freyre, 1969) no célebre Casa Grande e Senzala e desde então ficou associado às elites com tendências escravocratas. Quando mencionam as "privatarias tucanas" o autor do comentário ecoa uma representação presente em parte da esquerda brasileira sobre o processo de privatização no governo de Fernando Henrique Cardoso: a de que foi um processo corrupto e contra os interesses do povo brasileiro.

O debate político polarizado e radicalizado que marcou a disputa eleitoral para presidente em 2014 visibilizou, como poucas vezes na história, a dicotomia entre direita e esquerda no cenário político brasileiro. Não surpreende, portanto, que no material analisado, o movimento antipetista seja seguidamente definido como um movimento conservador, um movimento constituído e organizado pela direita política.

O que se pode deduzir pela movimentação do Cunha, é que ele quer tentar derrubar a Dilma antes de cair. Está ansioso pela condenação que o Nardes vai anunciar em breve. Talvez a mais consistente das possibilidades de impeachment. muito embora o FHC, queridinho da direita tenha feito as mesmas coisas no passado, sem ser importunado pelo TCU. Vamos ver o que acontecerá neste país, se os golpistas colocarem em ação seu intento (Comentário do dia 01/10/2015).

As contas descobertas na Suíça eram o batom na cueca que faltava para flagrar o Cunhão. Um tipo como esse só permanece livre porque é útil aos interesses dos conspiradores, entre os quais, amplos setores da Justiça, MPF e PF. São, afinal, seus congêneres. Formam a linha de defesa da Casa Grande. Quanto ao Cunhão, creio que sairá impune, quem quer apostar? (Comentário do dia 01/10/2015).

Verdade. Pois é né! O PIG todo, a rainha do PIG a Globo, e esse pessoal todo do resto do PIG reunido, e seus "aliados de plantão", etc precisam desesperadamente tirar o PT do poder e é por isso que fazem o que fazem diariamente com Dilma, Lula as imundices que fazem. Querem o Impeachment de todas as maneiras com seus golpismos habituais, pois não veem a hora de poderem "mamar" \$ para salvarem \$\$ e colocar no poderes novamente o "queridinho" deles, o PSDB, para assim, então, poderem voltar a ter o "status quo

", de domínio e "reinado" garantido como mais ou menos tinham antes... (Comentário do dia 29/09/2015)

Segundo Bobbio (1995) o critério que distingue a direita da esquerda é o modo como esses dois grupos avaliam a ideia de igualdade. A esquerda, diferentemente da direita, definiria a igualdade como um valor central para uma boa sociedade. Não surpreende, portanto, que essa centralidade da igualdade no ideário da esquerda seja sempre reafirmada quando definem a identidade da direita. A direita é apresentada como um grupo privilegiado ou que defende os interesses dos privilegiados.

Expressões como "queridinho da direita", "Casa Grande" e "status quo" de "domínio" e "reinado" posicionam o antipetismo como um movimento de direita e que, por isso, por ser de direita e representar a manutenção do "status quo", seria protegido por instituições jurídicas e policiais do Estado Brasileiro (o TCU, a Polícia Federal, o Ministério Público).

Nos textos acima, as expressões "derrubar a Dilma", "conspiradores", "tirar o PT do poder" e "golpismos habituais" acrescentam uma qualidade adicional aos direitistas. Eles não são somente defensores do status quo, eles golpeiam a democracia para manter os privilégios da "casa grande", são golpistas 
O uso do termo golpistas para nomear os adversários do PT ganhou força, no conflito político atual, após a grande manifestação do dia 15 de Março de 2015 na qual os organizadores, "Movimento Vem Pra Rua", "Movimento S.O.S Forças Armadas", "Movimento Brasil Livre", e eleitores e simpatizantes da direita nas redes sociais protestaram nas ruas do Brasil contra o governo do PT e pediram o impeachment da presidente Dilma Rouseff (Silva, 2015). Desde então, o termo golpista passou a fazer parte do repertório de combate do "petismo" e a mobilização desse termo só se acentuou depois da abertura do processo de impeachment da presidente na câmara dos deputados.

Em outros comentários, numa radicalização desse retrato dos antipetistas como direitistas autoritários, que é sempre, obviamente, também uma acusação e não uma constatação afetivamente neutra, os antipetistas são deslocados para a extrema direita.

São Paulo promove limpeza étnica e depois dizem que apartheid era na África do Sul (Comentário de 01/10/2015)

Chacina? Em São Paulo? Não. Deve ser alguma medida preventiva imaginada pelo governo tucano (Comentário de 01/10/2015)

Muito bem, Instituto Lula! Só não podem fazer como o Guido Mantega, que perdoou fascistas após ser insultos violentos em São Paulo. (Comentário de 01/10/2015)

Esse procedimento da polícia nada mais é do que a representação da direita fascista, raivosa e covarde! (Comentário de 03/10/2015)

Nesses comentários, os antipetistas são associados a alguns dos grupos políticos mais violentos do século XX, seja por meio do uso de algumas categorias ("direita fascista", "fascistas"), seja por meio de proposições (a afirmação de que o governo tucano de São Paulo "promove limpeza étnica", a afirmação implícita de que São Paulo adota um regime de apartheid) que os associam a regimes baseados na ideia de supremacia branca.

Os dois primeiros textos comentam a notícia do dia primeiro de outubro, intitulada "Jovens negros e pobres são maioria entre vítimas de chacinas". Neles, recursos retóricos como a ironia e o sarcasmo, usados nos comentários, são mobilizados para posicionar o PSDB, o principal adversário do PT no campo político brasileiro, como um partido de inspiração nazi-fascista.

Foi recorrente no material analisado o posicionamento dos antipetistas como antinacionalistas, e tacitamente 0 posicionamento dos petistas como nacionalistas, afinal, como afirma Jenkins (2004), afirmar algo dos outros é frequentemente uma maneira de dizer algo sobre nós. Tal posicionamento sempre era acompanhado de um tom acusatório.

Para a elite vira lata, e agentes da CIA como o José Serra, trabalhar para aumentar as exportações, e fazer 0 pais crescer é crime. Enquanto isso descaradamente trabalham para entregar as riquezas do Brasil ao capital internacional. Os Senadores José Serra, e Aloysio Nunes trabalham no senado federal abertamente para as empresas petroleiras dos EUA, principalmente a Chevron.(Comentário do dia 30/09)

Eles querem voltar ao poder. Mas querem parar com os investimentos feitos no país. Querem economizar 0 dinheiro para entregá-los aos estrangeiros. Eles não gostam de ver o Brasil progredir querem ver o Brasil pedindo esmolas aos estrangeiros(Comentário do dia 29/09).

Falando sobre a relação entre direita e nacionalismo, Barbosa (2008, p. 2) afirma: "O nacionalismo constituiu um componente fundamental das ideologias de direita". 
Sem dúvida, o nacionalismo é central na atuação de determinados grupos de direita, em determinados contextos. Só para citar o caso brasileiro, o nacionalismo era central no discurso daqueles que golpearam as instituições democráticas em 1964 (Skidmore, 1989; Skidmore, 2010). Mas o internacionalismo também está presente no pensamento de direita, principalmente nos agrupamentos de direita de tendência liberal ou neoliberal. Aqui no Brasil temos o caso do PSDB que nasceu como um partido social democrata e paulatinamente foi adotando princípios e práticas neoliberais e abraçando um internacionalismo inequívoco (Mesquita, 2010).

Essa dicotomia também está presente na esquerda. Não obstante o conhecido internacionalismo da esquerda marxista, esquerda que nasce convocando os trabalhadores de todo o mundo para a luta contra o capitalismo, como se pode ver em Marx e Engels (1998), o nacionalismo também está presente no pensamento de esquerda em determinados contextos sociais e históricos. $\mathrm{Na}$ esquerda brasileira, principalmente na esquerda trabalhista, 0 nacionalismo era um componente essencial, um componente que definia a identidade desse grupo político. Uma das principais acusações que os trabalhistas dirigiam aos seguidores da UDN de Carlos Lacerda era a acusação de "entreguismo", acusação que posicionava os udenistas como vassalos dos interesses de grupos internacionais que queriam saquear as riquezas do Brasil ( Skidmore, 1989; Skidmore, 2010).

$\mathrm{Na}$ análise do uso estratégico desses dois componentes, nacionalismo e internacionalismo, pode-se adotar o raciocínio semelhante ao desenvolvido pelos psicólogos discursivos Wetherell e Potter (1992) quando criticam a tendência de estudiosos do racismo para identificar alguns conteúdos discursivos como próprios de práticas racistas. Segundo esses autores, embora o racialismo (a crença na existência de raças) seja usado muito frequentemente para realizar práticas racistas, nem sempre é usado assim. Por outro lado, embora um discurso de tipo culturalista ou sociologizante seja muito frequentemente usado para desqualificar práticas racistas, ele pode ser usado para justificar e legitimar tais práticas. Também é assim na relação da direita e da esquerda com 0 nacionalismo e 0 internacionalismo. Nenhum desses discursos é essencialmente de esquerda ou de direita. Embora o internacionalismo talvez esteja mais presente historicamente nos agrupamentos políticos de esquerda e o nacionalismo talvez mais presente nos agrupamentos políticos de direita, os dois conteúdos são mobilizados por grupos de esquerda e de direita em diferentes contextos sociais e históricos em nome de objetivos políticos que eles, tacitamente ou não, apresentam como definidores de suas identidades: a igualdade, no caso da esquerda, e a liberdade, no caso da direita.

Nos comentários acima, o antinacionalismo dos inimigos do PT é associado à entrega das riquezas brasileiras aos estrangeiros e ao empobrecimento do Brasil. Quando afirmam que os antipetistas "trabalham para entregar as riquezas do Brasil ao capital internacional" e "querem economizar o dinheiro para entregá-los aos estrangeiros" revelam a força do discurso do trabalhismo fundado por Getúlio Vargas no modo como esses militantes definem o atual conflito político brasileiro, afinal o termo entreguismo e suas variantes são centrais nesse discurso. Certamente a relação de Paulo Henrique Amorim com o trabalhismo explica em parte esse vocabulário nos relatos dos frequentadores do site. 0 jornalista fazia frequentemente elogios ao trabalhismo de Vargas nas suas postagens. Mas, além disso, a presença desse vocabulário tem certamente relação com as transformações ideológicas do PT nos últimos anos (Singer, 2010). Nesse contexto, não surpreende que nos comentários acima, e em vários outros do mesmo tipo, a oposição entre burgueses e proletários seja substituída pela oposição entre uma elite "vira lata", que se alia aos estrangeiros para roubar as riquezas de todo o povo brasileiro, e os brasileiros nacionalistas. 


\section{Representando o "petismo"}

Os simpatizantes do "petismo" no site do jornalista Paulo Henrique Amorim definem-se frequentemente de maneira tácita, implícita. Por exemplo, quando acusam os antipetistas de golpismo, estão tacitamente posicionando a si mesmos como democratas.

Em outros momentos definem a si mesmos de maneira direta. Nesses momentos apresentam a si mesmos como vítimas de um golpe orquestrado por uma direita constituída pelo empresariado, a grande mídia e setores importantes do Estado brasileiro.

Posicionam-se nessa condição de vítima de duas maneiras. Em vários comentários os petistas são construídos como motivados e combativos, preparados para o confronto. Neles destaca-se o tom de resistência por meio do qual se posicionam incisivamente contra os adversários. Nesses relatos o povo está do lado deles, o povo é consciente, poderoso e está preparado para defender o PT.

Em contraste com essa posição supostamente ativa e aguerrida dos militantes, algumas vezes o partido é representado como passivo e até covarde. Um partido que não reage aos ataques dos seus inimigos, que não reagia à tentativa, naquele ano de 2015, de efetivar o processo de impeachment da presidente da república Dilma Rousseff.

Frequentemente os autores dos comentários aqui analisados usaram o termo "esquerda" ou outros do mesmo campo semântico para identificar a si mesmos e a todos os que apoiavam o PT no conflito político que se desenvolvia naquele ano de 2015.

A esquerda tem que ser perfeita, e a direita pode ser de qualquer maneira. Não existe um erro da esquerda, seria um erro teórico e unificado de toda a esquerda, primeiro a esquerda não é unificada, segundo tem visões diferentes e pra piorar é refém da realidade, ninguém faz o que quer, influencia a realidade tentando leva-la para onde queremos. Depois a esquerda não é formada por santos, mas sim por pessoas que defendem 0 trabalhador, as vezes um cara de direita é mais divertido, legal e bacana, mas defende privilégios e injustiças (Comentário do dia 01/10/2015).

Não me identifico com estes artigos desanimados, pungentes, purgativos, do professor Wanderley Guilherme dos Santos. Refutar a corrupção é um truísmo. Ninguém vai chegar aqui, nem o presidente da Câmara, e gritar "viva a corrupção". O PT (não confundir com a esquerda), dentro de um quadro de disputa extremada pelo poder, foi acusado pela principal força da oposição - a grande mídia - de roubo, desvio de dinheiro público, corrupção, etc. Ora, trata-se da velha farsa udenista a impressionar os incautos. Que mais poderíamos esperar? Aliás, acusar forças progressistas de corrupção, corrompê-las mesmo, é o primeiro item do beabá da CIA. Como pode a rede Globo acusar alguém de corrupção? Premiar juizes paladinos, que aceitam dócil e deslavadamente os prêmios? Enquanto o professor almeja "convocar os dispostos à longa reconstrução binstitucional do destacamento de vanguarda do país", os movimentos sociais de todas as procedências unem forças para a defesa de uma pauta progressista. A autocrítica da corrupção já está feita. O resto é penitência no claustro do PIG (Comentário do dia 01/10/2015).

Os acertos da esquerda são maiores que o da direita e os erros da esquerda não são engavetados (Comentário do dia 01/10/2015).

O PT foi fundado em 1980 num momento em que o regime militar começava a se enfraquecer e o país começava a se preparar para a redemocratização. Nasceu como um partido político de esquerda que acreditava no engajamento como motor para mudanças sociais (Samuels, 2004). Mas, como foi visto anteriormente com Singer 
(2010), depois de sua chegada ao poder federal, com a eleição para presidente de Luiz Inácio Lula da Silva, aos poucos se afastou da ideologia socialista que orientou a sua formação e se tornou muito semelhante ao PTB de antes de 1964. O partido se aproximou, portanto, segundo Singer, da esquerda populista, nacionalista, não marxista, tão característica da história política da América Latina, que no Brasil foi representada pelos herdeiros de Getúlio Vargas como João Goulart e Leonel Brizola.

Os comentários dos simpatizantes do Partido dos Trabalhadores aqui analisados, coerentemente com essa aproximação do partido em relação à esquerda trabalhista, mobilizam raramente o repertório revolucionário próprio do marxismo. Nos comentários acima, e em vários outros do corpus, estão presentes termos como "esquerda", "direita", "progressista" mas raramente termos que fazem parte do vocabulário do marxismo revolucionário. Por outro lado, mobilizam temas do discurso trabalhista repetidamente. No tópico anterior, se viu um exemplo disso, quando se abordou a acusação de antinacionalismo e entreguismo feita pelos simpatizantes do "petismo" quando definem os antipetistas.

De qualquer forma, esses simpatizantes não se constroem como um grupo homogêneo. Eles próprios ressaltam as fissuras no campo da esquerda, constroem uma identidade coletiva para si próprios que é bem parecida com a imagem de toda e qualquer identidade que está presente na obra dos teóricos do discurso Laclau e Mouffe (1985), para os quais identidades são construções precárias, marcadas por conflitos, divergências, disputas. No primeiro comentário se diz que a "esquerda não é unificada". No segundo comentário, o autor faz questão de distinguir o PT da esquerda em geral, mas ainda posiciona o partido no campo progressista ao afirmar que "acusar forças progressistas de corrupção, corrompê-las mesmo, é o primeiro item do beabá da CIA", ao posicioná-lo, portanto, como vítima de uma estratégia da direita capitalista norte-americana.

Nesse comentário, sugere-se que a situação política do PT não deve ser confundida com a da esquerda como um todo, que ele (o PT) acabou por se "amoldar aos limites da ordem que queria superar" (lasi, 2012, p. 359).

\section{CONSIDERAÇÕES FINAIS}

Neste trabalho procurou-se compreender como simpatizantes do Partido dos Trabalhadores estão construindo a identidade do "petismo" e do "antipetismo" na internet. Não apenas foi possível mapear os atributos identitários mobilizados pelos militantes e simpatizantes do petismo quando falam do adversário/inimigo e de si próprios, mas também foi possivvel apreender, num quadro geral, as nuances e contradições presentes no uso desses atributos.

Observou-se que a desonestidade, o conservadorismo e o antinacionalismo são traços centrais na identidade do "antipetismo" construída nos comentários aqui analisados. Ser de esquerda, por outro lado, apresenta-se como uma característica central desses simpatizantes do "petismo" quando falam de si mesmos. Por fazer parte da esquerda política, o PT, segundo eles, estaria sendo vítima de um golpe organizado por uma direita formada pelo empresariado, a grande mídia e setores do Estado brasileiro. Em alguns momentos esse movimento de direita é representado como uma força poderosa que fatalmente derrotará o PT; em outros é representado como um oponente que será facilmente derrotado pelas forças de esquerda apoiadas pelo povo.

Considera-se que este estudo amplia, ainda que de maneira modesta, a compreensão dos aspectos psicossociais do conflito político brasileiro que se exacerbou a partir do final de 2014. Mais especificamente, permite compreender como simpatizantes do partido político que foi expulso do poder por uma coalizão de direita e teve seu 
líder maior encarcerado construíam discursivamente, naquele momento tão agônico, aquele conflito e os seus atores coletivos. Conflito que está longe de ter terminado e que, ao menos retoricamente, se torna a cada dia mais violento.

\section{NOTAS}

\section{Notas}

1. No site Conversa Afiada os meios de comunicação tidos como inimigos do PT são nomeados com a sigla "PIG" que significa Partido da Imprensa Golpista.

\section{REFERÊNCIAS}

Abreu, J.M., \& Allegretti, G. (2016). Comportamento político violento e avanço global da direita. Crítica e Sociedade:
revista de cultura política,
6
(2),
88-121.
Recuperado
de

http://www.seer.ufu.br/index.php/criticasociedade/article/view/36545/20239

Antaki, C., \& Widdicombe, S. (2008). Identity as an achievement and as a tool. In: C. Antaki, \& S. Widdicombe (Eds.). Identities in talk (pp. 1-14). London: Sage.

Barbosa, J.R. (2008). Ideologia e intolerância: a extrema direita Latino-Americana e a atuação no Brasil dos herdeiros do eixo. Aurora, 2, 2-11. Recuperado de http://www2.marilia.unesp.br/revistas/index.php/aurora/article/view/1172

Benwell, B., \& Stoke, E. (2006). Discourse and identity. Edinburgh: Edinburgh University Press.

Billig, M. (1987). Arguing and Thinking: A Rhetorical approach to social psychology. Cambridge: Cambridge University Press.

Biroli, F., \& Mantovani, D. (2014). A parte que me cabe nesse julgamento; a Folha de S. Paulo na cobertura ao processo do "mensalão". Opinião Pública, $20 \quad$ (2), 204-218. Recuperado de http://www.scielo.br/pdf/op/v20n2/0104-6276-op-20-02-00204.pdf

Bobbio, N. (1995). Direita e esquerda: razões e significados de uma distinção política. São Paulo: Editora-Unesp.

Boisard, S. (2014). Pensando as direitas na América Latina: objeto científico, sujeitos e temporalidades?. Varia História, 30 (52), 85-100.

Brugnago, F., \& Chaia, V. (2015). A nova polarização política nas eleições de 2014: radicalização ideológica da direita no mundo contemporâneo do facebook. Aurora: revista de arte, mídia e política, 7 (21), 99-129. 
Delcourt, L. (2016). Um TeaParty tropical: a ascensão de uma "nova direita" no Brasil. Lutas Sociais, São Paulo, 20(36), 126-139.

Du Preez, P. (1980). The politics of identity: ideology and the human Image. New York: St.Martin's Preez.

Edwards, D. (2008). The relevant thing about her: social identity categories in use. In: C. Antaki, \& S. Widdicombe (Eds.). Identities in talk (pp. 15-33). London: Sage.

Foucault, M. (1972). A arqueologia do saber. Petrópolis: Vozes.

Freyre, G. (1969). Casa grande e senzala. Rio de Janeiro: Livraria José Olympio Editora. Giddens, A. (1996). Para além da esquerda e da direita: o futuro da política radical. São Paulo: Editora Unesp.

Gill, R. (2002). Análise de discurso. In: M. W. Bauer, \& G. Garskell (Orgs.). Pesquisa qualitativa com texto, imagem e som (pp.244-269). Rio de Janeiro: Vozes.

lasi, M. L. (2012). As metamorfoses da consciência de classe: o PT entre a negação e o consentimento. São Paulo: Expressão Popular.

Jenkins, R. (2004). Social Identity. London: Routledge.

Laclau, E., \& Mouffe, C. (1985). Hegemony and Socialist Strategy: towards a radical democratic politics. London: Verso.

Marx, K., \& Engels, F. (1998). Manifesto comunista. São Paulo: Boitempo Editorial. Mesquita, L. (2010). O pensamento internacionalista do PSDB: da adoção neoliberal à crítica ao Lula. Textos \& Debates, 18, 39-56.

Oliveira Filho, P., Feitosa, G.G., \& Silva, C. C. W. (2019). Petismo e Antipetismo em relatos de simpatizantes da direita na internet. Pesquisas e Práticas Psicossociais, $14 \quad$ (2), 1-13. Recuperado de http://pepsic.bvsalud.org/pdf/ppp/v14n2/16.pdf

Potter, J., \& Wetherell, M. (1987). Discourse and Social Psychology: Beyond Attitudes and Behaviour. London: Sage.

Potter, J. (1998). La representación de la realidad: Discurso, retórica y construcción social. Barcelona: Paidós.

Samuels, D. As bases do petismo. Rev. Opinião Pública, Campinas, v. 10, n.2, p. 221-241, 2004. Recuperado de http://www.scielo.br/pdf/op/v10n2/22016.pdf Santos, M.A. (2014).

Cartografias das redes da revolta: fluxos políticos de oposição radical no Facebook. Contemporânea, 12 106-120. Recuperado 
https://dadospdf.com/download/cartografia-das-redes-da-revolta-fluxos-politicos-de-oposiao-radical-no-facebook-_5a 44b06eb7d7bc891f78cbb1_pdf

Santos, F.L.B. (2018). Do lulismo a Bolsonaro: a agonia da nova república no Brasil. Boletín Onteaiken, 26, 1-16. Recuperado de http://onteaiken.com.ar/ver/boletin26/onteaiken26-01.pdf

Silva, I.G. Autoritarismo e conservadorismo na democracia brasileira: a direita brasileira mostra a sua cara nas ruas. São Luís, 2015.

Skidmore, T. (1989). Brasil: de Castelo a Tancredo. Rio de Janeiro: Paz e Terra.

Skidmore, T. (2010). Brasil: de Getúlio a Castelo (1930-64). São Paulo: Editora Schwarcz. Singer, A. (2010). A segunda alma do partido dos trabalhadores. Novos Estudos, 88, 89-111.

Van Dijk, T. A. (1987). Communicating racism: ethnic prejudice in thought and talk. London: Sage.

. (1992). Mapping the language of racism: discourse and the legitimization of exploitation. Hemel Hempstead: Harvester/Wheatsheaf and New York: Columbia University Pres 